\title{
EDITORIAL
}

\section{A new milestone for Palliative \& Supportive Care}

With the publication of Volume 14, Number 1 of our journal, Palliative \& Supportive Care, we have reached an important milestone. I am pleased to report that with this issue we are entering a new era in the publication of the journal, whose acceptance in the scientific and academic community is now well established. We had the idealistic mission of providing an intellectual and journalistic home for that small, but growing, band of academicians around the world who are focusing their work in palliative care, with particular emphasis on the psychiatric, psychosocial, existential, and spiritual aspects of care. We have done more than survive-we have thrived! Even in an environment where there are now close to 25 journals dedicated to palliative care and related topics, Palliative \& Supportive Care has stood out as an international scientific palliative care journal that has managed to maintain a "literary heart and soul." Our success is due in no small part to the contributions of hundreds of researchers and clinicians from around the world who have so graciously and generously shared their work with us for publication. Palliative \& Supportive Care is truly an international journal, with authors from over 25 countries submitting more than 2,000 manuscripts for publication to the journal these past 13 years. In 2013, we learned of a remarkable increase in our impact factor to 1.21, demonstrating the quality of the papers submitted and published, and the degree to which this work is referenced in the field by other authors. The fact is that the growth of our journal has been quite dramatic and exciting. In fact, it has reached a critical point where we now receive some 200 manuscripts a year to fill six published issues, including our "special issues" on topics of critical interest to our field. As a result of the success and growth of Palliative \& Supportive Care over the past 13 years, we have decided to reorganize our editorial process and refresh our International Editorial Board.

Starting with Volume 14, Issue 1, we will be moving to an editorial structure of an Editor-in-Chief and five Associate Editors. I will continue on as
Editor-in-Chief of Palliative \& Supportive Care, but I would like to take this opportunity to introduce our readers to our five Associate Editors. Each of the them represents a different area of specialty and discipline, as well as a diversity of regions around the world.

Harvey Max Chochinov, M.D, Ph.D., is a Distinguished Professor of Psychiatry at the University of Manitoba, Canada Research Chair in Palliative Care, Director of the Manitoba Palliative Care Research Unit Cancer Care-Manitoba, and Chair of the Canadian Virtual Hospice. Harvey has served as one of two International Co-Editors of the journal but is moving into the role of a senior Associate Editor, taking a more hands-on role in the journal's everyday activities. Besides being a lifelong close colleague and personal friend, he is perhaps the most visionary and prolific thought-leader in the area of psychiatric palliative care.

Simon Wein, M.D., is Director of the Department of Pain and Palliative Care at The Davidoff Cancer Center, Rabin Medical Center, in Petah Tikvah, Israel. Simon was the second of our founding International Co-Editors and is now taking on the role of Associate Editor. His expertise in palliative care, psycho-oncology, philosophy, and spirituality and his representation of the Middle East bring unique qualities to the journal.

Matthew J. Loscalzo, L.C.S.W., is the Liliane Elkins Professor in Supportive Care Programs and Administrative Director at the Sheri \& Les Biller Patient and Family Resource Center, and Executive Director of the Department of Supportive Care Medicine at the City of Hope Medical Center in Duarte, California. A social worker by discipline, Matt is one of the foremost authorities in the world on clinical service delivery, training, and clinical research in psychosocial palliative care. As one of our Associate Editors, he brings his vast experience, expertise, and humanity to assure the success and excellence of our journal.

Gian Domenico Borasio, M.D., is the Chair in Palliative Medicine at the University of Lausanne, 
and Chef du Service de Soins Palliatives at the Centre Hospitalier Universitaire Vaudois in Lausanne, Switzerland. Gian is a superb clinician and perhaps the foremost expert in the world on measure development and assessment of quality of life in the palliative care setting.

Allison J. Applebaum, Ph.D., is the Director of the Caregivers Clinic and Assistant Attending Psychologist in the Department of Psychiatry and Behavioral Sciences at the Memorial Sloan Kettering Cancer Center in New York. As a psychologist specializing in caregiver issues in oncology and palliative care, she brings several areas of expertise to the table in enhancing the group of our Associate Editors.

In addition to creating a new editorial structure that includes the five Associate Editors listed above, we have refreshed the Editorial Board. Special thanks go out to long-serving board members who are now serving as emeritus members, including Jimmie Holland, Lea Baider, Susan Block, Irene Higginson, Uwe Koch, and Neil MacDonald. We are pleased to have an extraordinarily distinguished and geographically diverse Editorial Board that includes such individuals as David Kisane, Eduardo Bruera, Holly Prigerson, Stein Kassa, Paul Jaconsen, Phyllis Butow, Luigi Grassi, Yosuke Uchitomi, Maggie Watson, Luzia Travado, Alan Valentine, Lori Weiner, Lili Tang, Friederic Stiefel, Tone Rustoen, Christina Puchalski, Michel Reich, Carla Ripamonti, Barry Rosenfeld, Brian Kelly, Carrie Lethborg, Madeline Li, Virginia Lee, Mark Lazenby, Wendy Lichtenthal, Patty Parker, Yesne Alici, Lisa Miller, Francisco Gil, Xavier Gomes-Batiste, Richard Fielding, Sylvie Dolbeault, Martin Fegg, Albert Diefenbacher, Linda Ganzini, Paul Glare, Nathan
Cherny, Maria Carlsson, Tatsuo Akechi, and Nessa Coyle.

Because we receive so many excellent submissions every year, we have revamped our instructions for authors to make it much clearer as to the types of articles we publish, and a new set of modest word limits has been instituted. I urge our authors to utilize the online submission system, which can be reached through the Palliative \& Supportive Care homepage at the Cambridge Journals Online website or directly through the following link: http://mc.manuscript central.com/pax.

Finally, a last word of appreciation and thanks to all who support our journal. Together we have created and nurtured something of value. Our creation is in its adolescence, still a bit vulnerable, and continually transforming. The future may be unknown, but today we look forward with hope and faith in ourselves and each other.

There's only us

There's only now

No other road

No other way

No day but today

- Jonathan Larson, Rent

WILLIAM BREITBART, M.D.

Chairman, Jimmie Holland Chair in Psychiatric Oncology Chief Psychiatry Service Department of Psychiatry and Behavioral Sciences Memorial Sloan-Kettering Cancer Center 641 Lexington Avenue, 7thFloor New York, New York 10022, USA 